\title{
HORMÔNIO FOLÍCULO ESTIMULANTE COMO PREDITOR DO ACHADO DE ESPERMATOZÓIDES MÓVEIS NA BIÓPSIA TESTICULAR DE CASOS DE AZOOSPERMIA
}

\author{
Carlos Augusto Bastos de Souza*, João Sabino Cunha Filho, Débora Santos, Ana Angélica Gratão, \\ Lauren Filippon, Cristiana Tedesco, Fernando freitas, Eduardo Pandolfi Passos \\ Setor de Reprodução Assistida / Hospital de Clínicas de Porto Alegre - \\ Universidade Federal do Rio Grande do Sul, Porto Alegre, RS.
}

RESUMO - Objetivo. Determinar fatores preditivos do achado de espermatozóides móveis em casos de azoospermia.

Métodos. Sessenta pacientes com diagnóstico de azoospermia tiveram avaliado seu volume testicular e dosagens séricas de hormônio folículo estimulante (FSH), hormônio luteinizante (LH), prolactina e testosterona. Os pacientes foram submetidos à biópsia testicular bilateral com anestesia local. As amostras obtidas foram submetidas à avaliação no laboratório de biologia de reprodução, sendo classificadas em: ausência de espermatozóides, presença de espermatozóides móveis e imóveis, e à avaliação histológica. Foram comparados: idade, valores hormonais, volume testicular e histologia com 0 achado de espermatozóides móveis. Foi considerado significativo um $P<0,05$.

Resultados. Quarenta e cinco pacientes possuíam azoospermia não-obstrutiva. Foi encontrada uma diferença significativa entre os grupos com achado de espermatozóides móveis e o grupo com ausência de espermatozóides quanto aos valores de FSH $(P=0,037$ ANOVA one-way). Foi construída uma curva ROC que determinou valores abaixo de $16,05 \mathrm{UI} / \mathrm{L}$ (sensibilidade de $76,2 \%$, especificidade de $67,7 \%$ ) como preditivos do achado de espermatozóides móveis. Não foram encontradas outras diferenças estatísticas.

Conclusōes. O FSH possui boa acurácia na determinação da presença de espermatozóides móveis na biópsia testicular de pacientes azoospérmicos. 0 exame físico, os valores de testosterona, LH e prolactina não podem ser utilizados na predição do sucesso da biópsia testicular para fins de reprodução assistida.

Unitermos: Azoospermia. Biópsia. Infertilidade masculina. Espermatozóides imóveis.

\section{INTRODUÇÃO}

AICSI (intracytoplasmic sperminjection)é uma técnica estabelecida para o tratamento de uma série de condições de infertilidade masculina, modificando situações que há pouco tempo não possuíam opções ${ }^{1,2}$. No Brasil, em 1995, casais com causa masculina severa começaram a obter gestações e a modificar o perfil de desesperança presente nesses casos ${ }^{3}$. O uso de espermatozóides testiculares de pacientes com azoospermia ${ }^{4,5}$ em ICSI ampliou as indicações da técnica para esses pacientes. No entanto, em muitos casos, espermatozóides móveis não podem ser encontrados em amostras testiculares a fresco ou após descongelamento ${ }^{6}$. Autores descreveram uma menor taxa de fertilização e gestação com uso de

*Correspondência:

Setor de Reprodução Humana / Hospital de Clínicas de Porto Alegre

Universidade Federal do Rio Grande do Sul R. Ramiro Barcelos, 2350/s. 1135

Porto Alegre - Brasil - CEP 90035-003

F: (51) 3316-8117 - casouza@via-rs.net espermatozóides imóveis quando comparados com o uso de espermatozóides móveis ${ }^{7}$. Outros autores têm descrito taxas aceitáveis de fertilização, mas com piores resultados ${ }^{8}$.

Os procedimentos de obtenção de espermatozóides podem não apresentar sucesso, principalmente nos pacientes portadores de azoospermia não-obstrutiva ocorrendo falha em obter espermatozóides em até $50 \%$ dos $\operatorname{cas}^{6,9}{ }^{6,9}$. Isto pode acarretar a perda de ciclos de indução da ovulação, bem como estresse e desgaste psicológico ao casal ${ }^{10}$. Somam-se a esses fatores as complicações da biópsia testicular como alterações na vascularização, desenvolvimento de hematomas e infecção". Devido a esses fatos, a busca de fatores preditivos do achado de espermatozóides em casos de azoospermia é uma necessidade.

Testes de rastreamento devem possuir alta sensibilidade para incluir todos os casos da doença e baixos níveis de falso-negativos, evitando a perda de casos. Autores recomendavam que o FSH fosse utilizado como marcador da presença de espermatogênese, sendo utili- zado como fator de triagem ${ }^{12}$. Outros autores não conseguiram identificar o $\mathrm{FSH}$ como um fator preditivo adequado do achado de espermatozóides ${ }^{13}$. Recentes relatos procuraram associar a inibina-B como um útil marcador da espermatogênese e demonstram que a produção de inibina-B somente estaria presente quando houvesse atividade espermatogênica ${ }^{14}$. Outros autores revelaram que apesar da melhor sensibilidade, a inibina $B$ não possuiria capacidade de predizer o achado de espermatozóides em casos de azoospermia não-obstrutiva ${ }^{15}$.

A busca de outros marcadores como a análise histológica prévia, ou a presença de espermátides, também foi realizada por outros autores ${ }^{6,9}$, demonstrando serem melhores marcadores do sucesso da obtenção, no entanto, apresentando um alto índice de falsonegativos. Assim, tem sido descrito que pacientes não devem ser excluídos do procedimento de obtenção de espermatozóides baseado em parâmetros hormonais, citológicos, histológicos ou genéticos ${ }^{9,13}$. Devido a carência de um consenso na literatura, realizamos 
este estudo a fim de avaliar fatores preditivos do achado de espermatozóides móveis em casos de azoospermia em pacientes submetidos à biópsia testicular.

\section{Métodos}

\section{Delineamento}

Foi realizado um estudo transversal no setor de Reprodução Humana do Hospital de Clínicas de Porto Alegre, no período entre janeiro de 1998 e dezembro de 2001.

\section{Pacientes}

Foram estudados 60 pacientes com diagnóstico de azoospermia não-obstrutiva e obstrutiva. Os pacientes com azoospermia obstrutiva possuíam indicação de biópsia testicular por falha de obtenção de espermatozóides através de punção aspirativa do epidídimo. $O$ diagnóstico de azoospermia foi realizado através da ausência de espermatozóides em três espermogramas de rotina seguidos de centrifugação. Os pacientes foram submetidos a uma avaliação inicial composta de história clínica e exame físico. Na história clínica foram destacados: o desenvolvimento puberal, a cirurgias prévias, a história reprodutiva, infecções genitais, exposição a substâncias tóxicas e uso de fármacos. O exame físico foi realizado pelo mesmo examinador onde foram avaliados os caracteres sexuais secundários, exame do genital e avaliação do volume testicular com um orquidômetro de Prader. Os pacientes foram classificados segundo o volume testicular em normal ou diminuído utilizando como ponto de corte 0 valor de $15 \mathrm{~cm}^{3(16)}$. Os dados da anamnese, exame físico e dosagens hormonais foram utilizados para classificar os pacientes em azoospermia obstrutiva e não-obstrutiva.

Os pacientes com estigmas ao exame físico de anormalidades cromossômicas foram submetidos a cariótipo de sangue periférico. Os pacientes com agenesia de ductos deferentes fizeram triagem para possíveis mutações do gene da fibrose cística. Todos os pacientes foram informados e foi obtido consentimento escrito para participação no estudo. O estudo foi aprovado pela comissão de Ética em Pesquisa do Grupo de Pesquisa e Pós-graduação do Hospital de Clínicas de Porto Alegre (n॰ 028/98).

\section{Dosagens hormonais}

Os pacientes foram submetidos a dosagens hormonais de FSH, LH, prolactina e testosterona total na primeira de consulta de avaliação diagnóstica. As amostras foram centrifugadas a velocidade de $2500 \mathrm{rpm}$ para separação do plasma e congeladas a $-20^{\circ} \mathrm{C}$ para analise posterior. Os hormônios $\mathrm{FSH}$, $\mathrm{LH}$, e prolactina foram analisados por quimioluminescência utilizando kits comerciais (Immulite Ltda ${ }^{\circledR}$, USA), as dosagens de testosterona total foram realizadas por radioimunoensaio com kit comercial (INC ${ }^{\circledR}$, Germany). As variações inter e intrakits foram $5,45 \%$ e $13,3 \%$ para prolactina, $2,8 \%$ e $4,2 \%$ para FSH, $2,6 \%$ e $3,8 \%$ para $\mathrm{LH}$ e $3,3 \%$ e $4,9 \%$ para testosterona total. Os kits não demonstraram uma reação cruzada significante entre os hormônios avaliados.

\section{Obtenção de espermatozóides}

Os pacientes foram submetidos à biópsia testicular previamente ao ciclo de ICSI sob anestesia local com lidocaína $0,5 \%{ }^{17}$. Uma pequena incisão longitudinal escrotal foi realizada com exposição da túnica albugínea e visualização dos vasos subtúnicos. Duas ou três incisões foram realizadas na túnica albugínea em diferentes posições de cada testículo, evitando-se os vasos. Com secção tecidual e compressão testicular foi realizada a extração de tecido testicular. As amostras foram divididas em quartis, sendo o primeiro quarto colocado em solução de Bouin e enviado para análise histológica e restante colocado em uma placa de Petri e enviado imediatamente para o laboratório de biologia da reprodução situado na sala ao lado.

\section{Processamento da amostra}

As amostras foram processadas de forma similar àquela descrita por Silber et al. $(1996)^{18}$. O tecido testicular foi colocado em uma placa de Petri contendo um mililitro de meio PI (Irvine ${ }^{\circledR}$ ), acrescido de 10\% de SSS (Syntetic Substitute Serum, Irvine ${ }^{\circledR}$ ) e macerado com o auxílio de duas lâminas de bisturi. O fluido foi centrifugado a $1000 \mathrm{~g}$. O sobrenadante foi desprezado e o "pellet" ressuspendido em I ml de meio (PI + SSS). O mesmo volume de meio de congelação (Test Yolk Buffer, Irvine ${ }^{\circledR}$ ) foi adicionado e o volume final acondicionado em palhetas de $0,5 \mathrm{ml}$. A congelação foi realizada expondo as palhetas ao vapor de nitrogênio $\left(-120^{\circ} \mathrm{C}\right)$ por 20 minutos e transferindo-as para o nitrogênio líquido, onde ficaram armazenadas.

As amostras foram classificadas quanto ao achado de espermatozóides em três grupos: presença de espermatozóides móveis, presença de espermatozóides imóveis na amostra e ausência de espermatozóides na amostra.

\section{Análise histológica}

A histologia foi realizada no laboratório de patologia do nosso serviço. As porções de tecido testicular após serem fixadas em solução de Bouin foram reidratadas através de um gradiente de álcool e xileno. Em seguida, foram coradas com hematoxilina e eosina e examinadas através de microscopia óptica pelas técnicas padrões com aumento de 100 a 1000 vezes. A histologia foi classificada em cinco categorias: espermatogênese normal, hipoespermatogênese, "Sertoli Cell-Only Syndrome", parada de maturação espermática e esclerose tubular. Foram considerados casos de hipoespermatogênese a presença de túbulos seminíferos contendo poucas espermátides e diminuição no número de espermatogônias e espermatócitos primários. O diagnóstico de síndrome células de Sertoli foi dado quando os túbulos seminíferos apresentavam apenas células de Sertoli. O diagnóstico de parada de maturação foi dado quando havia menos do que 17 espermatogônias por túbulo e menor número de espermatócitos primários com espermátides ausentes. $O$ diagnóstico de esclerose tubular compreendeu os casos com ausência de células germinativas e de células de Sertoli. Os patologistas não possuíam qualquer informação quanto às características do caso ou quanto ao resultado do achado de espermatozóides no laboratório de biologia da reprodução.

\section{Análise estatística}

Aanálise estatística foi realizada utilizando o programaSPSS9.0. As variáveis quantitativas foram analisadas utilizando análise de variância com um critério de classificação(ANOVAoneway) e o teste de Bonferroni utilizado para discriminar as diferenças. As variáveis categóricas foram avaliadas utilizando teste $c^{2} \mathrm{e} / \mathrm{ou}$ teste exato de Fisher. Foram construídas curvas ROC para análise dos diferentes valores preditivos das variáveis quantitativas. Na curva ROC foi determinado o ponto com maior 
Tabela I - Distribuição do achado de espermatozóides segundo as diversas variáveis avaliadas

\begin{tabular}{|c|c|c|c|c|}
\hline & $\begin{array}{l}\text { Móveis } \\
n=13\end{array}$ & $\begin{array}{c}\text { Imóveis } \\
n=26\end{array}$ & $\begin{array}{c}\text { Ausentes } \\
n=21\end{array}$ & $\begin{array}{c}\text { Estatistica } \\
P\end{array}$ \\
\hline Idade(anos) & $39,23( \pm 6,7 I)$ & $36,81( \pm 5,68)$ & $38,29(3,98)$ & $0,557^{\mathrm{a}}$ \\
\hline $\mathrm{FSH}(\mathrm{U} / \mathrm{L})$ & $9,89 *( \pm 11,14)$ & $14,87( \pm 10,58)$ & $20,15 *( \pm 10,20)$ & $0,031^{a}$ \\
\hline $\mathrm{LH}(\mathrm{U} / \mathrm{L})$ & $6,37( \pm 4,38)$ & $9,73( \pm 6,78)$ & $13,5( \pm \mid 1,09)$ & $0,058^{a}$ \\
\hline Prolactina(ng/ml) & $7,23( \pm 2,35)$ & $8,24( \pm 3,57)$ & $7,79( \pm 3,12)$ & $0,589^{a}$ \\
\hline Testosterona(ng/ml) & $3,86( \pm 0,67)$ & $4,04( \pm 0,72)$ & $4,37( \pm 1,02)$ & $0,146^{a}$ \\
\hline \multicolumn{5}{|l|}{ Volumetesticular $\left(\mathrm{cm}^{3}\right)$} \\
\hline normal & II & 20 & 13 & \\
\hline reduzido & 2 & 6 & 8 & $0,335^{\mathrm{b}}$ \\
\hline
\end{tabular}

a-ANOVAone-way

b-Teste exatode Fisher

Tabela 2 - Distribuição dos diagnósticos histológicos segundo o achado de espermatozóides

\begin{tabular}{|c|c|c|c|}
\hline & $\begin{array}{l}\text { Móveis } \\
(n=\mid 3)\end{array}$ & $\begin{array}{l}\text { Imóveis } \\
(n=26)\end{array}$ & $\begin{array}{l}\text { Ausentes } \\
(n=21)\end{array}$ \\
\hline Espermatogênese & 5 & 7 & I \\
\hline SertoliCell-OnlySyndrome & 2 & 4 & 6 \\
\hline Paradadematuração & 0 & 3 & 4 \\
\hline Hipoespermatogênese & 6 & 12 & I \\
\hline Esclerosetubular & 0 & 0 & 9 \\
\hline
\end{tabular}

Figura I - Curva ROC dos valores de FSH quanto ao achado de espermatozóides móveis na amostra

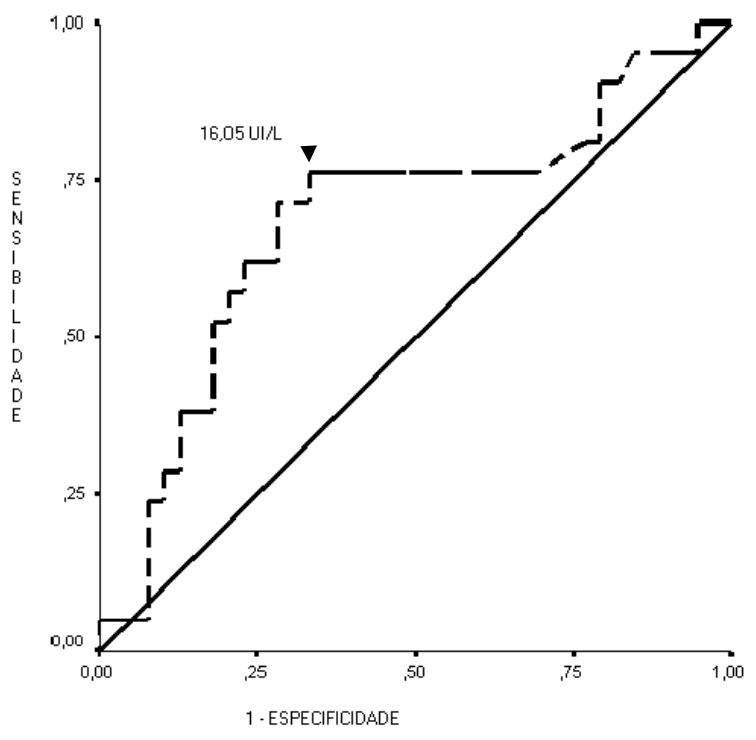

Rev Assoc Med Bras 2003; 49(2): 167-72 acurácia para o achado de espermatozóides móveis quando comparado com a ausência de espermatozóides na biópsia testicular. Foram considerados significativos $\mathrm{P}<0,05$.

\section{Resultados}

A amostra consistiu de 60 pacientes, 45 deles $(75 \%)$ possuíam diagnóstico de azoospermia não-obstrutiva. Os espermatozóides foram obtidos com sucesso em 39 (65\%) casos, sendo $14(93,3 \%)$ casos de azoospermia obstrutiva e $25(45,5 \%)$ casos de azoospermia não-obstrutiva.

A Tabela I mostra os resultados de achado de espermatozóides das variáveis pesquisadas. Foi encontrada uma diferença estatisticamente significativa entre os grupos com presença de espermatozóides móveis e ausência de espermatozóides quanto aos valores de $\mathrm{FSH}(P=$ $0,037)$. As demais variáveis não demonstraram diferenças estatisticamente significativas.

A predição segundo os valores de FSH do achado de espermatozóides móveis na amostra foi calculada segundo uma curva ROC demonstrada na Figura I. Segundo a avaliação da curva ROC, o melhor valor de FSH como fator preditivo do achado de espermatozóides móveis foram valores abaixo de 16,05 UI/L sensibilidade de $76,2 \%$ e especificidade de $67,7 \%$. A Tabela 2 descreve o achado de espermatozóides segundo o tipo histológico.

\section{Discussão}

O estudo demonstrou que valores de FSH abaixo de 16,05 UI/L estão associados ao achado de espermatozóides móveis em casos de azoospermia submetidos à biópsia testicular. Nossos dados são indicativos de que os valores de FSH são capazes de predizer o achado de espermatozóides móveis em casos de azoospermia. Não foi encontrada correlação entre o achado de espermatozóides na biópsia testicular e ovolume testicular e outras dosagens hormonais. Nossos achados suportam a idéia de que o FSH possui uma correlação com a espermatogênese testicular.

A obtenção de espermatozóides em pacientes com diagnóstico de azoospermia não-obstrutiva é uma realidade e mesmo pacientes com volume testicular reduzido, consistência testicular alterada e níveis de FSH elevados possuem possibilidade de apresentarem focos de espermatogênese ${ }^{19}$. 
Autores demonstraram uma associação entre os níveis de $\mathrm{FSH}$ e o grau de patologia testicular $^{20}$. Autores ${ }^{17}$, analisando 86 pacientes com azoospermia não-obstrutiva, demonstraram que o grupo com menores valores de FSH possuía maior chance de sucesso no procedimento de obtenção de espermatozóides. Outros trabalhos demonstraram resultados similares demonstrando uma recuperação espermática inversamente proporcional aos valores de $\mathrm{FSH}^{9,13}$. No entanto, esses trabalhos apesar de indicarem uma correlação entre FSH e espermatogênese, carecem de valor preditivo para presença de espermatozóides móveis para ICSI.

É difícil determinar com certeza uma população onde o procedimento de biópsia não deva ser realizado. Pois quando assumirmos um ponto de corte para indicação do procedimento, poderemos ter pacientes que, mesmo com valores altos de FSH, apresentem espermatozóides, no entanto a presença de espermatozóides móveis nesses casos é muito difícil. Em nosso trabalho, a população com baixa chance de obter espermatozóides móveis em um procedimento de obtenção de espermatozóides possuía valores de FSH acima de I6,05 UI/L.

A taxa de falso-negativos do FSH na literatura parece diminuir sua utilidade para uso clínico em predizer com certeza a taxa de recuperação de espermatozóides. $A$ associação do $\mathrm{FSH}$ com a inibina $B$ que foi proposta na literatura ${ }^{14}$, poderia aumentar o poder da avaliação diagnóstica desses pacientes. Esses autores demonstraram que a acurácia do volume testicular e do FSH são similares, ao redor de $70 \%$ na predição do sucesso da FIV, e colocaram que a utilização da inibina $B$ como marcador da espermatogênese deveria ser estimulada pela sua maior acurácia diagnóstica $(94,1 \%)^{14}$. Em nosso trabalho, não utilizamos a dosagem de inibina $B$ para avaliação hormonal dos casos de azoospermia, pois quando iniciamos o trabalho, em 1998, o uso da inibina B para avaliação da espermatogênese ainda não estava validado, o que aconteceu com o decorrer dos anos. No entanto, apesar dos achados desses autores sobre seu valor preditivo, outros autores ${ }^{15}$ encontraram resultados desfavoráveis. Este estudo, ao avaliar a inibina $B$, demonstrou que a mesma possuiria um melhor poder discriminativo da espermatogênese do que o FSH, mas que ainda assim não era capaz de predizer com certeza $\circ$ achado de espermatozóides, questionando seu valor clínico em pacientes com azoospermia obstrutiva e nãoobstrutiva ${ }^{15}$. Dessa forma, os dois hormônios parecem realizar uma melhor avaliação do estado da espermatogênese, mas ainda assim não são capazes de discriminar com a certeza necessária 0 achado de espermatozóides, podendo ser classificados como exames úteis sem serem definitivos sobre o resultado da obtenção de espermatozóides.

Em nosso trabalho encontramos a associação do $\mathrm{FSH}$ com o achado de espermatozóides móveis. Em 1999, autores demonstraram que ICSI com uso espermatozóides imóveis apresentavam menores taxas de fertilização e gestação, sem, no entanto, haver diferença significativa no número de embriões e potencial de implantação ${ }^{8}$. Anteriormente, em 1995, já haviam sido descritas menores taxas de fertilização com uso de espermatozóides totalmente imóveis do ejaculado, provavelmente devido a alta taxa de necrospermia e a injeção de espermatozóides mortos $^{21}$. A avaliação de vitalidade por outras formas que não a motilidade são necessárias para o uso de espermatozóides imóveis em ICSI. Apesar do desenvolvimento de testes hiposmótico atóxicos ao espermatozóide e de outros testes como a razão cabeça-cauda ${ }^{22}$, todos esses procedimentos implicam em manipulação espermática e potenciais lesões à membrana plasmática e diminuição de sua capacidade fertilizante. Sendo assim, a capacidade preditiva do achado de espermatozóides móveis, que possuem sua viabilidade facilmente avaliada, torna-se muito importante.

Os outros parâmetros hormonais estudados - LH, prolactina, testosterona total - não apresentaram qualquer associação com o achado de espermatozóides móveis ou imóveis. Esses dados estão em concordância com o consenso atual da carência desses hormônios supracitados na possibilidade de predição do achado de esper- matozóides ${ }^{6,9,13}$. Isto provavelmente ocorre porque esses hormônios são muito mais utilizados como diagnóstico de patologias concomitantes que possam estar ocorrendo do que representativos do estado de espermatogênese testicular.

Não enfocamos as diferenças encontradas na avaliação histológica e o achado de espermatozóides. Pelo fato de tratar-se de uma amostra contendo pacientes com azoospermia obstrutiva e não-obstrutiva, essas diferenças eram esperadas. No entanto, 0 fator mais importante para 0 desinteresse nesse tipo de avaliação, em nossa opinião, é a falta de praticidade do critério histológico para predição do achado de espermatozóides. Um teste de triagem deve possuir as seguintes características: praticidade, mínima invasividade, reprodutibilidade, alta sensibilidade e especificidade.

Apesar da avaliação histológica possuir uma boa correlação com o achado de espermatozóides como demonstrado anteriormente ${ }^{6,13}$, não possui nenhuma das outras características aventadas. Além disso, não possui valor para os pacientes em início de avaliação, que não foram submetidos a nenhum procedimento cirúrgico testicular e, portanto, não possui o resultado da avaliação histológica previamente a realização de um procedimento de obtenção de espermatozóides. Os parâmetros histológicos muitas vezes falham em predizer o resultado da biópsia, pois mesmo a ausência de espermatozóides em uma biópsia prévia não garante que múltiplas biópsias sejam capazes de obter espermatozóides ${ }^{13}$. Muitas vezes, focos de espermatogênese podem estar presentes, independente de parâmetros histológicos e clínicos.

Em nosso trabalho, obtivemos um recuperado de espermatozóides menor que o ideal, porém dentro dos parâmetros descritos na literatura ${ }^{6,9}$. Este baixo recuperado poderia ser explicado por dois fatores: realização do estudo em uma população com alta prevalência de falência gonadal ou a análise de apenas um quadrante do testículo através da biópsia testicular. Freqüentemente, o parênquima testicular apresenta uma histologia heterogênea e a realização de múltiplas biópsias 
poderia aumentar o recuperado de espermatozóides. Por outro lado, a realização de múltiplas biópsias pode aumentar o risco de complicações por alterações na vascularização testicular podendo acarretar a atrofia testicular.

Um teste que possuiria características de baixo custo, praticidade e mínima invasividade é a análise do volume testicular através do exame físico. Em nosso trabalho não fomos capazes de encontrar qualquer associação entre o volume testicular e 0 achado de espermatozóides, conforme já descrito por outros autores ${ }^{\prime 3}$. Isto ocorre provavelmente pela ampla variedade de diagnósticos clínicos e histológicos que esses pacientes possuem, não sendo possível traçar uma correlação entre o volume testicular e o diagnóstico do paciente.

\section{Conclusóes}

A avaliação e orientação do paciente com azoospermia que será submetido a um procedimento de obtenção de espermatozóides pode ser feita com base nos valores de FSH.

\section{SUMMARY}

Follicle stimulating HORMONe AS PREDICTOR OF MOBILE SPERMATOZOA IN TESTICULAR BIOPSY OF AZOOSPERMIC PATIENTS

OBJECTIVE. To define predictive factors of mobile spermatozoa recovery in azoospermic patients.

Methods. Testicular volume, serum follicle stimulating hormone (FSH), luteinizing hormone $(L H)$, prolactin (PRL) and testosterone levels were assessed in 60 azoospermic patients. Patients underwent bilateral testicular biopsy with local anesthesia. Samples were classified according to absence of spermatozoa, presence of motile and nonmotile spermatozoa, and histological findings. Age, hormone levels, testicular volume and histology with motile spermatozoa recovery were compared. $P<$ 0.05 was considered significant.

RESULTS. Non-obstructive azoospermia was diagnosed in 45 patients. Significant differences were detected between the group with motile spermatozoa recovery and the group with absence of spermatozoa in terms of FSH levels $(P=0.037$ ANOVA oneway). A ROC curve was used to define FSH values below $16.05 \mathrm{IU} / \mathrm{L}$ (sensitivity: $76.2 \%$, specificity: 67.7\%) as predictive factors for motile spermatozoa recovery. Other statistical differences were not detected.

CONCLUSIONS. FSH levels below $16.05 \mathrm{IU} /$ $L$ showed good accuracy to predict the presence of motile spermatozoa in the testicular biopsy of azoospermic patients. Physical examination, testosterone levels, $L H$ and prolactin were not useful as predictive factors in the present study. [Rev Assoc Med Bras 2003; 49(2): 167-72]

KEY wORDs: Azoospermia. Biopsy. Masculine infertility. Immotile spermatozoa.

\section{REFERÊNCIAS}

I. Palermo G, Joris H, Devroey P, Van Steirteghem AC. Pregnancies after intracitoplasmic sperm injection of single spermatozoon into an oocyte. Lancet 1992; 340: 17-8.

2. Sousa M, Fernandes S, Barros A. Prognostic factors for successful testicle spermatid recover. Mol Cell Endocrinol 2000; 166:3743.

3. FrancoJr., Petersen CG, Mauri AL, Baruffi RL, Freitas EF, Ursolino G. Tratamento do fator masculino grave em infertilidade pela injeção intracitoplasmática de espermatozóides. Primeiras gestações obtidas com a coleta de espermatozóides do testículo. RBGO 1995; 17:967-76.

4. Devroey P, Liu J, Nagy Z, Tournaye H, Silber SJ, Van Steirteghem AC. Normal fertilization of human oocytes after testicular sperm extraction and intracytoplasmic sperm injection. Fertil Steril I 994; 62: 639-4I.

5. Silber SJ, Van Steirteghem AC, Liu J, Nagy Z, Tournaye H, Devroey P. High fertilization and pregnancy rate after intracytoplasmic sperm injection with spermatozoa obtained from testicle biopsy. Hum Reprod 1995; 10: 14852.

6. Mulhall JP, Burgess CM, Cunningham D, Carson R, Harris D, Oates R. Presence of mature sperm in testicular parenchyma of men with nonobstrutive azoospermia: prevalence and predictive factors. Urol 1997; 49: 91-7.

7. Nagy ZP, Joris H, Verheyen G, Tournaye H, Devroey P, Van Steirteghem AC. Correlation between motility of testicular spermatozoa, testicular histology and the outcome of intracytoplasmic sperm injection. Hum Reprod 1998; 13: 890-5.

8. Shulman A, Feldman B, Madgar I, Levron J, Mashiach S, Dor J. In-vitro fertilization treatment for severe male factor: fertilization potential of immotile spermatozoa obtained by testicular extraction. Hum Reprod 1999; 14:749-2.

9. Ezeh UIO, Moore HDM, Cooke ID. Correlation of testicular sperm extraction wit morphologial, biophysical and endocrine profiles in men with azoospermia due to primary gonadal failure. Hum Reprod 1998; 13:3066-74.

10. Ben-Yosef D, Yogev L, Hauser R, Yavetz H, Azem F, Yovel I, et al. Testicular sperm retrieval and cryopreservation prior to initiating ovarian stimulation as the first line approach in patients with non-obstrutive azoospermia. Hum Reprod 1999; 14:|794-80|.

II. Schlegel PN, Su LM. Physiological consequences of testicular sperm extraction. Hum Reprod 1997; 12:688-92.

12. Hargreave TB, Jequier AM. Can follicle stimulating hormone estimation replace testicular biopsy in the diagnosis of obstructive azoospermia? Br J Urol I 978; 50:4I5-8.

13. Tournaye H, Verheyen G, Nagy P, Ubaldi F, Goossens A, Silber S, et al. Are there any predictive factors for successful testicular sperm recovery in azoospermic patients? Hum Reprod 1997; 12:80-6.

14. Ballescá JL, Balasch J, Calafell JM, Alvarez R, Fábregues F, Osaba MJM, et al. Serum inhibin $B$ determination is predictive of successful testicular sperm extraction in men with nonobstrutive azoospermia. Hum Reprod 2000; 15:1734-8.

15. Von Eckardstein S, Simoni M, Bergmann M, Weinbauer GF, Gassner P, Schepers AG, et al. Serum inhibin $B$ in combination with serum follicle-stimulating hormone ( $\mathrm{FSH}$ ) is a more sensitive marker than serum FSH alone for impaired spermatogenesis in men, but cannot predict the presence of sperm in testicular tissue samples. J Clin Endocrinol Metab 1999; 84:2496-50I.

16. Sigman M, Lipschultz LI, Howardz SS. In: Lipshultz LI, Howards SS. Evaluation of Subfertile male. St Louis: Mosby Year Book; 1991.p.I79.

17. Westlander G, Hamberger L, Hanson C, Lundin K, Nilsson L, Söderlund B, Werner C, Bergh C. Diagnostic epididymal and testicular sperm recovery and genetic aspects in azoospermic men. Hum Reprod 1999; 14:118-22. 
18. Silber SJ, Van Steirteghem AC, Nagy Z. Normal pregnancies resulting from testicular sperm extraction and intracytoplasmic sperm injection for azoospermia due to maturation arrest. Fertil Steril 1996; 66:331-4.

19. Cha KY, Oum KB, Kim HJ. Approaches for obtaining sperm in patients with male factor infertility. Fertil Steril 1997; 67: 985-95.

20. Yaman O, Özdiler E, Seckiner I, Gögüs O.
Significance of serum FSH levels and testicular morphology in infertile males. Int Urol Nefrol 1999; 31:519-23.

21. Nagy ZP, Verheyen G, Liu J, Joris H, Janssenzwillen C, Wisanto $A$, et al. Results of 55 intracytoplasmic sperm injection cycles in the treatment of male immunological infertility. Hum Reprod 1995; 10: 1775-80.

22. Marmar JL, Corson SL, Gibbs M, Huszar G.
Tail to head ratio of fresh and frozen testicular sperm as measure of viability. J Androl 1998; 19(Suppl): 58.

Artigo recebido: 02/07/02

Aceito para publicação: 02/01/03 